\title{
Mitral valve surgery: comparison between superior septal and left atrial approaches
}

DOI: https://doi.org/10.32007/jfacmedbagdad.6241810

$\begin{array}{ll}\text { Abdulsalam Y. Taha* } & \text { FICMS } \\ \text { Shkar R Haji Saed* } & \text { FICMS } \\ \text { Amanj K Mohammed* } & \text { FICMS } \\ \text { Jivara H Nadr* } & \text { MSc }\end{array}$

c) (i) (8)

This work is licensed under a Creative Commons Attribution-NonCommercial 4.0 International License

\section{Abstract:}

Background Mitral valve (MV) is one of the most complex structures in human heart with a challenging exposure. Traditionally, MV is approached via left atriotomy (LAA) while superior septal approach (SSA) is an alternative.

Objective: is to highlight the merits and demerits of these two approaches in providing access to the MV

JFac Med Baghdad 2020; Vol.62, No. 4

Received: Dec. 2020 Accepted: Feb. 2021 Published: Feb. 2021 in term of the aortic cross clamp time (ACCT), quality of exposure, and potential complications in view of the published literature.

Patients and Method: Over an 18-month period ending at June $30^{\text {th }}, 2019,56$ patients with MV disease \pm other cardiac diseases were enrolled in this study. Twenty patients had surgery via LAA (one surgeon) whereas 36 were operated upon via SSA (another surgeon). Standard surgery was done via median sternotomy, cardiopulmonary bypass and hypothermia of $32{ }^{\circ} \mathrm{C}$. Perioperative events were recorded.

Results In SSA group (males=25; age ranged 23-74 years; mean=57.4), patients had chest pain and breathlessness for a mean of 3 months (>LAA) besides low ejection fraction (EF) in 44\%, atrial fibrillation (AF) in $38.9 \%$ and dilated LA in $19.4 \%$. They underwent $25 \mathrm{MV}$ replacements (MVR), $11 \mathrm{MV}$ repairs (0 in LAA), 11 coronary artery bypass grafts (CABGs) (2.6 graft per patient vs. 1.3 in LAA; significant) and 2 aortic valve replacement. Mean ACCT was 81.6 minutes ( $<$ LAA). Postoperatively, 32 patients $(88.9 \%)$ had a normal or improved EF, 11 of 14 AF patients (78.6\%) reverted to sinus rhythm and no hospital death was recorded. Conclusion Besides excellent exposure, the SSA enabled us to perform MVR or repair \pm additional interventions within a short time and without a heart block. Hence, our results matched the international literature.

Keywords: Left atrium, mitral valve exposure, left atrial approach, superior septal approach.

\section{Introduction:}

Mitral valve (MV) is one of the most complex structures in the human heart [1]. Hence, maximum exposure is mandatory for performance of a meticulous MV surgery particularly valve repair or replacement of a calcified valve $[1,2]$. Mitral valve exposure is more challenging than other valves as the access to the MV is mostly through the left atrium (LA) which is a deeply located, immobile, and thin-walled cardiac chamber with a limited space for incision [1]. Moreover, the MV is too far from the operating surgeon and faces towards his left shoulder in a way preventing him from seeing it en face $[2,3]$.

* Corresponding author: Dept. of Thoracic and Cardiovascular Surgery, College of Medicine, University of Sulaymaniyah.

Email: abdulsalam.taha@univsul.edu.iq shkar.cardiacsurgery@gmail.com dr.amanj@yahoo.com,dr.guevara77@gmail.com
Besides these anatomical facts, a small size of LA and the presence of adhesions of previous operation further increase the difficulty of MV exposure [4]. Plenty of approaches have been utilized to access the MV [4-20]. However, the 2 most commonly utilized approaches are the conventional left atriotomy (LAA) (used since 1960s) and the superior transseptal (septal) (SSA) proposed by Berreklouw et al [17] and Guiraudon et al [11] and currently has been adopted by several health care centers $[2,4,12]$. In left atriotomy, the right atrium (RA) is dissected off the LA, followed by an incision in the wall of LA while in the superior septal approach, the RA is incised first, followed by an incision in the atrial septum which is extended then to the dome or the roof of the LA [3]. Both left atriotomy and superior septal approaches have merits and demerits [15]. On one hand, the LAA is a time-tested technique which provides a satisfactory exposure of MV particularly in good-sized left atria. However, MV exposure is reported to be less 
than optimum with this approach in calcified valves, small atria or in the presence of adhesions of the redo cases $[2,4]$. On the other hand, all authors agree that the SSA provides an excellent and unprecedented exposure of MV especially in small atria, repeat operations on the MV or when concurrent tricuspid valve (TV) intervention is needed [6, 11, 17]. The main disadvantage, however, is the inevitable injury of sinoatrial (SA) nodal artery during right atrial incision part of the SSA [4] which yields controversial effects on occurrence of heart block [14, 15]. Most authors believe that heart block is not a concern $[11,17]$ while some worn that this complication is real and deserves a caution $[9,12]$. The aim of this study was to compare the outcome of both techniques as practiced in our locality and to present our one-surgeon single-center initial experience with SSA for MV surgery and discuss the results in view of the international literature.

\section{Patients and Methods:}

Over an 18-month period ending at June $30^{\text {th }}, 2019,56$ patients (males, $n=32$ ) with MV disease (MVD) \pm other cardiac diseases were admitted to Cardiac Surgery Departments in 2 cardiac centers in our city and underwent surgery either via LAA $(n=20)$ or via SSA $(n=36)$ following the preference of the surgeon. The study was approved by the Medical College Ethical Committee. The Institutional Review Board (IRB) approval number is 7/12/3488 at 9/10/2019.

Following a thorough clinical assessment, specific investigations were performed such as chest radiography, electrocardiography (ECG) and transthoracic echocardiography (TTE). Coronary angiography was arranged for males $>40$, females $>45$ and for younger patients if they had risk factors of coronary artery disease (CAD). Most patients were admitted one day before surgery with all investigations performed beforehand. Four units of cross-matched blood, 4 units of fresh frozen plasma (FFP) and 300-600 $\mathrm{ml}$ of single donor platelets made ready. Warfarin, aspirin and clopedogril were stopped 5-7 days prior to surgery. Furthermore, informed consent was obtained. Surgery was done via a full median sternotomy, cardiopulmonary bypass (CPB) and hypothermia of 32 ${ }^{0} \mathrm{C}$. The first group underwent surgery via the standard LAA (Figure-1) [3]. The second group had surgery through SSA (Figures 2-4) [3]. "The superior transseptal approach is essentially a combination of the transseptal approach and left atrial dome approach. A right atrial incision was made extending from lateral to the inferior vena cava (IVC) cannula inferiorly up into the right atrial appendage. Stay sutures were placed. A transseptal incision was made into the fossa ovalis then carried superiorly up and through the middle of the right atrial appendage onto the dome of the left atrium $1 \mathrm{~cm}$ lateral to the aorta and then just lateral to the left atrial appendage. Additional stay sutures were then placed into the left atrial/septal incision. Limited manual traction with spoon retractors was applied by the assistant" [3]. Consecutive left atrial dome, fossa ovalis and RA incisions were then closed in the appropriate anatomical position.

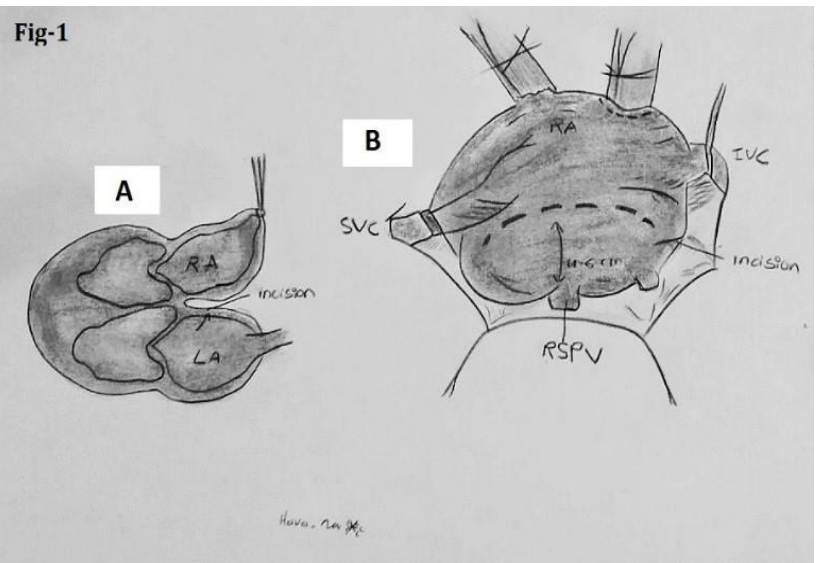

Figure-1: Left Atriotomy Approach

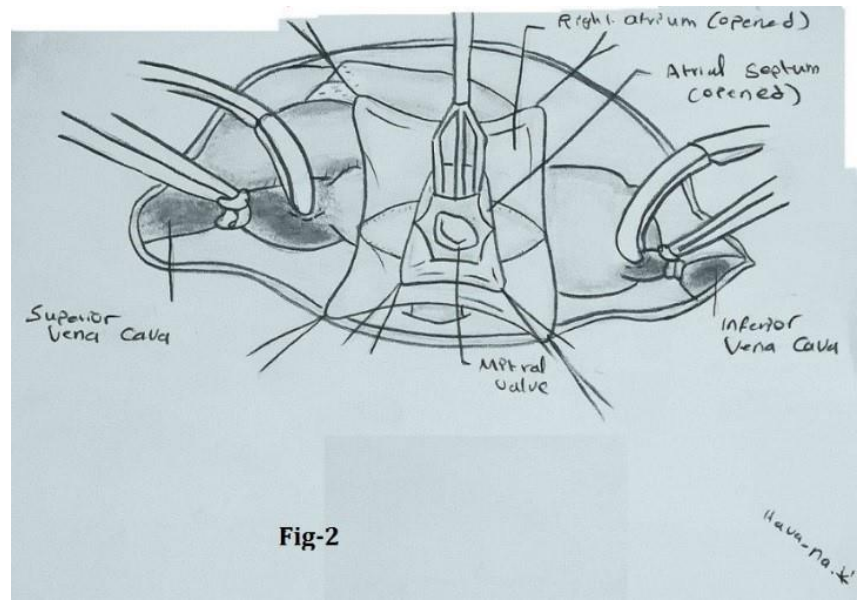

Figure-2: The Transseptal Approach.

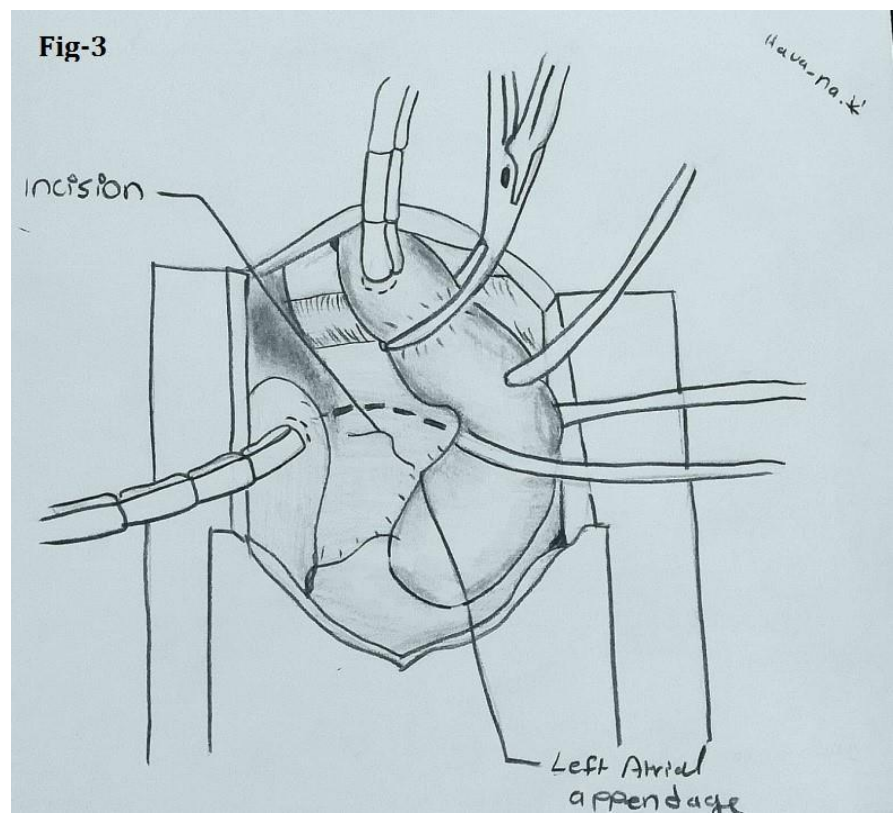

Figure-3: The Dome Approach. 


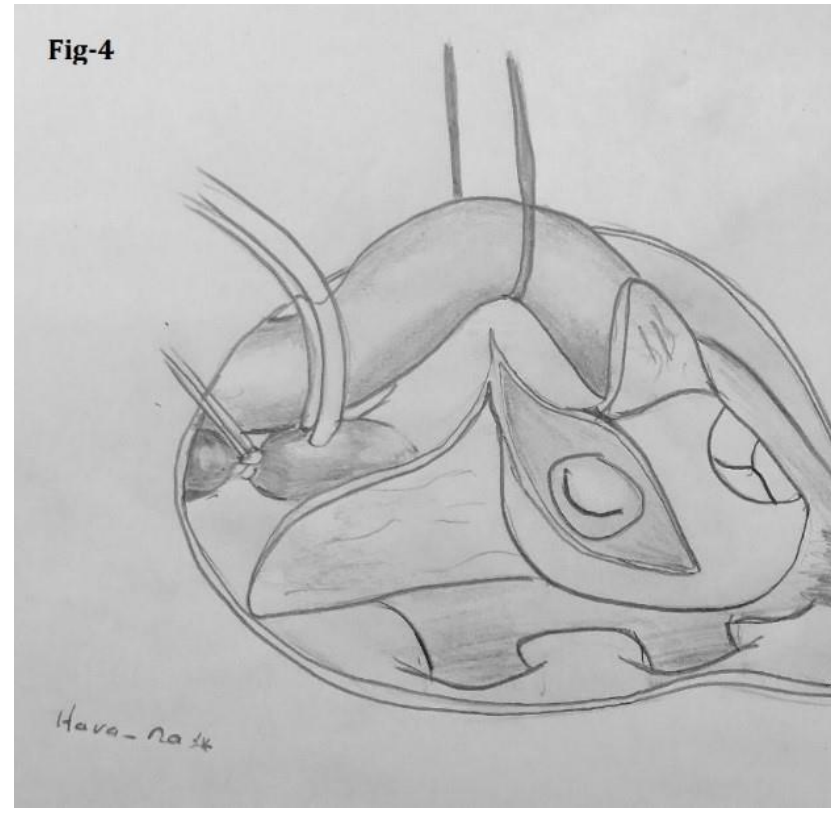

Figure-4: The Superior Transseptal Approach.

Intraoperative events such as $\mathrm{CPB}$ time and aortic cross clamp time (ACCT) were measured. Severely diseased MVs were replaced. Otherwise, repair was offered for other valves. Concomitant aortic valve disease was dealt with by repair or replacement while associated CAD was treated by coronary artery bypass graft (CABG). In the latter patients, distal coronary anastomoses were performed first. At the conclusion of operation, temporary pacing wires were routinely placed. All patients were admitted to the intensive care unit (ICU) for 1-2 days. Extubation was usually performed within 6-8 hours unless the patients were

Table-1: Age and Sex Distribution of Patients.

\begin{tabular}{|c|c|c|c|c|c|}
\hline \multirow[t]{2}{*}{ Age (years) } & \multicolumn{2}{|l|}{ Group 1(LAA) } & \multicolumn{2}{|c|}{ Group 2 (SSA) } & \multirow[t]{2}{*}{ Total, n (\%) } \\
\hline & Males, n (\%) & Females, n (\%) & Males, n (\%) & Females, n (\%) & \\
\hline $21-30$ & 0 & 0 & 0 & 1 & $1(1.8)$ \\
\hline $31-40$ & 0 & 0 & 1 & 0 & $1(1.8)$ \\
\hline $41-50$ & 3 & 4 & 7 & 2 & $16(28.6)$ \\
\hline $51-60$ & 3 & 5 & 6 & 3 & $17(30.4)$ \\
\hline $61-70$ & 1 & 4 & 9 & 3 & $17(30.4)$ \\
\hline $71-80$ & 0 & 0 & 2 & 2 & $4(7)$ \\
\hline Total & $7(12.5)$ & $13(23.2)$ & $25(44.6)$ & $11(19.7)$ & $56(100)$ \\
\hline
\end{tabular}

In group 1, females were almost double the males (13: 7 ) while in group 2 ; males were almost double the females (25: 11). Overall, the peak incidence of MVD \pm other cardiac diseases was in the $5^{\text {th }}-7^{\text {th }}$ decades $(\mathrm{n}=50,89.3 \%)$. The presenting symptoms were chest pain $(n=48)$ and breathlessness $(n=41)$ with a mean duration of 2.6 months and a range of 1-10 months. All patients had CXR, ECG and TTE. The latter was greatly helpful in diagnosis of cardiac valve lesions. In regard to coronary angiography, it was normal in 34 , abnormal in 17 and not done in 5 young patients having no risk of CAD. Abnormal coronary angiography comprised 3 vessel disease (9 in group 2), 2 vessel disease (2 in over 70 or had a risk of postoperative bleeding in such a case extubation was deferred for 12 hours.

Postoperatively, all patients received un-fractionated heparin (UFH) 5,000 IU bid for 2 days. Besides heparin, patients with mitral valve replacement (MVR) received warfarin $5 \mathrm{mg}$ tab o.d. Warfarin dose was then adjusted to achieve a target international normalized ratio (INR) of 3-3.5. Furthermore, preoperative B-blockers, antihypertensive and anti-diabetic medications were continued if they were already prescribed. Early postoperative events like volume of blood drainage, arrhythmia in the first 24 hours, heart block, central nervous system (CNS) complications, re-exploration for bleeding and death were documented. Each patient was seen at least 3 times for follow up (10 days, 3 months and 6 months after surgery). In each visit, clinical evaluation, ECG and TTE were performed. Besides the function of valve prosthesis and ejection fraction (EF) measurement, the presence of heart block and other types of rhythm disorders were noted. In this study, an EF > 55\% was considered normal. The data of all patients were entered into a database specifically designed using Microsoft Access 2010 program. Pertinent results were then retrieved via specifically made queries and analyzed thereafter. Statistical analysis was performed using $\mathrm{Z}$ test for 2 population proportions and $\mathrm{T}$-test for 2 independent means.

\section{Results}

The age range and mean \pm SD for Group 1 (LAA) was $41-68,53.9 \pm 8.2$ year while for Group 2 (SSA) it was $23-74,57.4 \pm 11.1$ year with no significant difference at $\mathrm{p}<0.05$. Female proportions were almost the same but males were more predominant in the SSA group. Table1 shows the age and sex distribution of patients. group 1) and 6 patients with 1 vessel disease (4 in group 1 and 2 in group 2).

Table-2 shows distribution of patients according to EF. Overall, 24 of 56 patients (42.9\%) had a subnormal EF prior to surgery. The proportion in group 1 was 8 of 20 (40\%) while in group 2 it was 16 of $36(44.4 \%)$.

Table-2: Preoperative EF

\begin{tabular}{llllll}
\hline \multirow{2}{*}{ EF } & \multicolumn{2}{l}{ Group 1(LA) } & \multicolumn{2}{l}{ Group 2 (SS) } & Total \\
\cline { 2 - 5 } & Males & Females & Males & Females & \\
\hline $\begin{array}{l}\text { Normal } \\
(>55)\end{array}$ & 5 & 7 & 14 & 6 & 32 \\
\hline $\begin{array}{l}\text { Subnormal } \\
\text { (below 55) }\end{array}$ & 2 & 6 & 11 & 5 & 24 \\
\hline Total & 7 & 13 & 25 & 11 & 56 \\
\hline
\end{tabular}


Table-3 shows ECG findings. It is evident that some patients had more than one ECG finding. ST elevation and $\mathrm{T}$ inversion indicate ischemic changes in patients with associated CAD. P mitrale and AF could result from LA dilatation while tall $\mathrm{R}$ and deep $\mathrm{S}$ waves could be attributed to LV hypertrophy (LVH). Both LA dilatation and LVH may accompany MVD.

Table-3: Preoperative ECG Findings

\begin{tabular}{llllll}
\hline \multirow{2}{*}{ ECG Finding } & \multicolumn{2}{l}{ Group 1(LA) } & \multicolumn{2}{l}{ Group 2 (SS) } & \multirow{2}{*}{ Total } \\
\cline { 2 - 5 } & Males & Females & Males & Females & \\
\hline Sinus rhythm & 1 & 4 & 2 & 2 & 9 \\
\hline ST elevation & 5 & 11 & 14 & 8 & 38 \\
\hline LBBB & 6 & 7 & 8 & 4 & 25 \\
\hline AF & 4 & 7 & 9 & 5 & 25 \\
\hline LA dilatation & 0 & 1 & 6 & 1 & 8 \\
\hline P mitrale & 1 & 2 & 4 & 1 & 8 \\
\hline T inversion & 0 & 3 & 6 & 0 & 9 \\
\hline Tall R wave & 0 & 0 & 0 & 1 & 1 \\
\hline Deep S wave & 0 & 0 & 0 & 1 & 1 \\
\hline Total & 17 & 35 & 49 & 23 & 124 \\
\hline
\end{tabular}

Table-4 shows types of surgery.

\begin{tabular}{|c|c|c|c|c|c|}
\hline \multirow{2}{*}{$\begin{array}{l}\text { Type } \\
\text { Surgery }\end{array}$} & \multicolumn{2}{|c|}{ Group 1 (LA) } & \multicolumn{2}{|c|}{ Group 2 (SS) } & \multirow[t]{2}{*}{ Total } \\
\hline & Males & Females & Males & Females & \\
\hline MVR & 3 & 8 & 11 & 4 & 26 \\
\hline MV Repair & 0 & 0 & 4 & 4 & 8 \\
\hline $\mathrm{MVR}+\mathrm{AVR}$ & 1 & 2 & 1 & 1 & 5 \\
\hline MVR+CABG & 3 & 3 & 7 & 1 & 14 \\
\hline $\begin{array}{l}\text { MV Repair+ } \\
\text { CABG }\end{array}$ & 0 & 0 & 2 & 1 & 3 \\
\hline Total & 7 & 13 & 25 & 11 & 56 \\
\hline
\end{tabular}

Isolated MV surgery was performed in 34 cases (60.7\%). Double valve surgery was performed for 3 patients in group $1(15 \%)$ vs. 2 patients in group 2 $(5.6 \%)$ [Statistically non-significant at $\mathrm{p}<0.05$ ].
Overall, CABG was performed 17 times (30.4\%); 6 times in group $1(30 \%)$ vs. 11 times in group $2(30.6 \%)$ [Statistically non-significant at $\mathrm{p}<0.05$ ]. It is of interest to note that none of the patients in group 1 had MV repair while 11 patients $(30.6 \%)$ in group 2 had MV repair. More coronary vessels per patient were revascularized in group 2 vs. group 1 (2.6 vs. 1.3). CPBT range, mean \pm SD was $80-284,139 \pm 49.7$ minute in group 1 vs. $75-199,111.3 \pm 33.2$ minute in group 2 (non-significant at $\mathrm{p}<0.05$ ). While ACCT range, mean \pm SD was $65-226,111.7 \pm 41.4$ minute in group 1 vs. 43 $129,81.6 \pm 21.3$ minute in group 2 (significantly shorter in group 2 at $\mathrm{p}<0.05$ ).

The early postoperative course was smooth. Of 25 patients with preoperative AF, 14 returned to sinus rhythm in the first day after surgery. There was neither heart block nor other types of arrhythmias. Moreover, no patient experienced CNS complication and no patient was in need of re-exploration for bleeding. The range of hospitalization period in group 1 (LAA) was 4 -7 days with a mean of $5.4 \pm 0.8$ day while in group 2 (SSA), it was 4-8 days with a mean of $5 \pm 1$ day. However, the difference was not statistically significant at $\mathrm{p}<0.05$.

One lady of 68 with MV repair via the SSA was diagnosed with infective endocarditis (IE) 3 months following surgery. She received a conservative treatment and was advised for redo surgery but she refused and was lost for follow up thereafter. A man of 49 with replacement of aortic and mitral valves through the SSA died 3 months postoperatively due to thrombosed aortic valve prosthesis as he stopped warfarin 1 month prior to his death. The state of patients at their last follow up visit is shown in Table-5.

Table-5: Last Follow Up Findings

\begin{tabular}{llllll}
\hline \multirow{2}{*}{ Finding } & \multicolumn{2}{l}{ Group 1(LAA) } & Group 2 (SSA) & Total \\
\cline { 2 - 5 } & Males & Females & Males & Females & \\
\hline Normal EF & 5 & 9 & 14 & 7 & 35 \\
\hline Subnormal but improved EF & 1 & 3 & 8 & 3 & 15 \\
\hline Well-functioning Prosthesis & 7 & 13 & 17 & 6 & 43 \\
\hline Well-functioning repaired MV & 0 & 0 & 7 & 4 & 11 \\
\hline Slow AF & 0 & 4 & 8 & 3 & 7 \\
\hline Reverted to normal sinus rhythm & 4 & 3 & 0 & 0 & 18 \\
\hline Heart Block & 0 & 0 & 55 & 25 & 0 \\
\hline Total & 17 & 32 & 1 & 129 \\
\hline
\end{tabular}

No heart block was diagnosed and all valve prostheses and repairs were properly functioning. Moreover, 18 of 20 patients (90\%) in group 1 and 32 of 36 patients (88.9\%) in group 2 had either normal or improved EF postoperatively.

\section{Discussion}

In 1991, Guiraudon et al published a paper in the Annals of Thoracic Surgery describing the (Extended Vertical Transatrial Septal Approach) as a new approach for MV exposure. Till that time, cardiac surgeons preferred to expose the MV via a median sternotomy approach and incising the LA in the region of the interatrial sulcus. Guiraudon et al used the newly described approach in 34 patients in whom MV was repaired in 17 and replaced in 17. Neither bleeding nor dysfunction of the atrioventricular or sinus node were encountered. The authors attributed their routine use of the new approach to the excellent exposure achieved in all cases regardless the morphology and size of the heart. They believed that MV operation was made easier and shorter as ACCT for isolated MV procedures was just 45 minutes and one hour in case additional procedures were performed simultaneously [11]. Noteworthy that 
Berreklouw et al in the same year (1991) published a paper in the same journal (Annals of Thoracic Surgery) named (Combined Superior-Transseptal Approach to the Left Atrium) describing their initial experience with this approach. The authors have used this approach in 22 patients in whom MV repair was offered for 14 and replacement for 8 . Mitral valve operation was combined with other cardiac procedures in 18 patients $(82 \%)$ and was performed as a reoperation in 3 patients (14\%). In all cases there was excellent exposure of the complete mitral annulus and subvalvar apparatus. There were no instances of postoperative bleeding, conduction defects, or intraatrial shunting related to the approach [17]. Similar to Berreklouw et al [17] and Guiraudon et al [11] who reported their experience in 1991, Kara and Kartufan from Turkey published a recent publication in 2018 describing identical results in using the SS approach. Twenty patients underwent MVR and 6 of them had additional interventions without procedurerelated complications. They correctly believed that excellent visualization of the operative area is the key for a successful mitral valve surgery. "Previous heart operation, being obese or thin, etiology of mitral valve disease and associated small size of the LA are factors affecting surgical vision" [19]. In the present series, we have operated upon 36 patients through the SS approach in whom 25 were replaced and 11 were repaired with results similar to Guiraudon et al and others $[11,17,19]$. Our ACCT was significantly shorter than LA approach. We think that the excellent exposure of the MV provided by the SS approach enabled us to perform MV procedures quicker thus compensating for the time required to close the "bigger SS incision". Kara and Kartufan [19] as well as others $[4,18]$ believe that using consecutive RA, fossa ovalis and left atrial dome incisions and closing these incisions in the appropriate anatomical position instead of reaching the MV with a single left atriotomy increase the cross-clamp time. However, the clear exposure provided by the SS approach technically facilitates the intervention to the MV especially in patients with a smaller LA diameter. When SS approach is used in such cases, it ensures a smooth valve surgery via a wide and good exposure without a need for a retractor but just stay sutures [19]. It is of interest to note that none of our patients in LA group had MV repair while 11 patients (30.6\%) in the SS group had MV repair. Assuming that both surgeons had a similar expertise and efficiency in performing MV surgery, this difference could be attributed to the nature of MVD in both groups i.e., mitral valves in LA group could have been heavily calcified and irreparable. In our study, MVR was performed more frequently than repair $(n=25,69.4 \%)$. This could be explained by the type and severity of MVD in our series compared to others. Mitral valve repair has been widely regarded as the optimal surgical procedure to treat mitral valve dysfunction of all etiologies. Data suggests that repair is associated with mortality and survival benefit, along with greater freedom from thromboembolic complications [20]. "The ideal approach to the mitral valve should give an undistorted exposure of the complete mitral annulus and subvalvar apparatus from a short distance, without damage to the surrounding structures". The SS approach to the left atrium fulfilled the aforementioned definition proposed by Berreklouw et al, and therefore it became their approach of choice in all primary and most repeat procedures of isolated or combined mitral valve operations [17]. The percentage of concurrent operations in SS approach group in our study was $36.1 \%(\mathrm{n}=13 ; 11 \mathrm{CABG}$ and 2 AVR). Patients with MVD associated with CAD have usually small left atria and they are usually scheduled for operation depending on the coronary artery anatomy, before the left atria have time to enlarge. Hence, the limited operation area in such patients demands an incision which provides an optimum exposure namely the superior septal [4]. It is also noteworthy that only (19.4\%; $n=7$ patients) in SS group in the present study had LA dilatation. i.e., the majority of patients $(n=29$; $80.6 \%$ ) had normal-sized or small left atria. Cardiac pathologies may change the anatomy of the LA and MV. Calcifications around the MV ring and hypertrophic RV may contribute to the small size of the LA. Additionally, scars and adhesions lead to mobility loss in the MV and surrounding tissues and make surgery more difficult. In contrast, with rheumatic mitral stenosis and chronic severe mitral regurgitation, the LA is generally quite large, and this can provide excellent exposure with left atriotomy [19]. Although our series did not include redo cases, Escobar et al described using 3 variations of transseptal approach (including SS) in operating easily upon 39 cases of MVD of which 31 cases were repeat operations $\left(2^{\text {nd }}\right.$ surgery $[\mathrm{n}=25], 3^{\text {rd }}$ surgery $[\mathrm{n}=5]$ and $4^{\text {th }}$ surgery $[n=1])$ with no complications associated with any of these approaches [7]. Likewise, El Saegh et al used the transseptal approach for small LA $(\mathrm{n}=5)$, adhesions from previous cardiac surgery or rheumatic activity $(n=9)$; large, organized left atrial thrombus $(n=1)$; concomitant tricuspid valve surgery $(\mathrm{n}=14)$; or a combination of these indications [15]. Furthermore, Malik and Kilic recommend the transseptal approach to be used in obese patients [14]. The salvage of the sinus node function in SS approach is surprising as the sinus node artery is vulnerable to injury either by the incision of the right atrium or the left atrium [11]. In $60 \%$ of the patients, the artery of the SA node crosses the roof of the LA after arising from the right coronary artery [18]. In a study done by Takeshita et al, 9 patients underwent pre- and post-operative coronary angiographies and confirmed that the SA node artery had been completely divided by SS incision [13]. However, normal sinus node function seems to be not entirely dependent on the blood supply by the sinus node artery. This is suggested by experiments of sinus node isolation, cardiac transplantation in which the heart of the recipient remains in sinus rhythm and the superior approach to the mitral valve [11]. Although sinus node dysfunction 
is one of the main concerns following MV surgery with the SS approach, its exact mechanism remains uncertain. Berdajs [cited in 19] claimed that possible injury of the sinus node artery during the SS approach is related to ischemia of the sinus node and results in sinus node dysfunction. In another hypothesis, Lukac stated that the incision in the SS approach creates a barrier to impulses from the sinus node, which is located on the posterior of the RA, preventing them from reaching the other side of the heart [12]. Despite division of the sinus node artery, 26 of 32 patients in Kon et al series with sinus rhythm prior to surgery remained in sinus rhythm postoperatively [8]. The problem of sinus node dysfunction after the SS approach obviously has implications for the surgeon's choice of the approach. To assess if sinus node dysfunction really is a clinically significant problem, Lukac et al retrospectively analyzed the need for pacemaker implantation on a large cohort of patients after MV surgery with long-term follow-up. Nineteen patients had a pacemaker implanted because of sinus node dysfunction; 9 in SS group and 10 in LA group. The SS approach was an independent risk factor of pacemaker implantation because of SA node dysfunction. They concluded that the SS approach has a higher risk of clinically significant sinus node dysfunction than the LA approach [12]. Opposite to the findings of the study above, postoperative electrocardiographic and electrophysiological studies done by Takeshita et al revealed that the sinus node function after the SS approach was relatively well maintained for more than one year after the operation. The influence of the SS approach on the SA node function in the mid-term postoperative period was apparently mild and did not cause a serious problem [13]. An interesting observation reported by Borracci et al is the possibility that the SS approach facilitates the recovery of sinus rhythm in patients with previous atrial fibrillation. From patients who had previous atrial fibrillation $(n=18), 83.3 \%$ recovered high sinus or junctional rhythm during the postoperative period [18]. Likewise, 11 of 14 patients $(78.6 \%)$ with preoperative AF in our study reverted to sinus rhythm within 6months. In Kon et al series, Twenty-seven of 37 patients with AF preoperatively had AF postoperatively while 8 changed to sinus rhythm after surgery [8]. In two publications dated 2003 [9] and 2016 [10], GarciaVillarreal et al reported their experience with the SS approach. Cardiac rhythm disturbances related to the unavoidable SA node artery transection in SS approach have been argued. Most patients with prior normal sinus rhythm in their series recovered this normal rhythm at hospital discharge.

\section{Conclusion}

Both left atrial and superior septal approaches have merits and demerits. The preference of the surgeon in choosing the approach remains an important factor as well as MV disease characteristics such as small LA, adhesions and redo surgery. Our one-surgeon singlecenter initial experience in SS approach suggest that it is effective for safe performance of MVR or reconstruction \pm additional interventions within a short operating time with results matching the relevant published literature. Accordingly, the SSA is favored and recommended.

\section{Authors' contributions}

Abdulsalam Y Taha contributed to study conception, study design, acquisition of data analysis, interpretation of data, drafting of manuscript and critical revision. Shkar R Haji Saed and Jivara H Nadr contributed to study conception, study design and interpretation of data. Amanj K Mohammed contributed to study conception.

\section{Acknowledgement}

We wish to thank Dr. Havana H. Nadr for drawing the figures of our paper

\section{References}

[1] Zhu X, editor. Surgical Atlas of Cardiac Anatomy. Beijing, China. Springer and Peoples Medical Publishing House; 2015

[2] Loberman D, Pirundini PA, Byrne JG, Cohn LH. Mitral Valve Repair. In: Cohn LH, Adams DH, editors. Cardiac surgery in the adult.5thed. New York. McGraw-Hill Education; 2018

[3] Kaneko T, Yammine M, Loberman D, Arank S. Mitral Valve Replacement. In: Cohn LH, Adams DH, editors. Cardiac surgery in the adult. 5th ed. New York. McGraw-Hill Education; 2018

[4] Aydin E, Arslan A, Ozkokeli M. Comparison of superior septal approach with left atriotomy in mitral valve surgery. Rev Bras Cir Cardiovasc 2014;29(3):367-73

[5] Glower DD. Surgical approaches to mitral regurgitation. J Am Coll Cardiol 2012;60:1315-22

[6] Sultan I, Trivedi DP, Machiraju VR. Surgical approaches to the mitral valve: variable paths to the same destination. Indian Journal of Thoracic and Cardiovascular Surgery 2018;34(2):105-112

[7] Escobar FS, Gallardo GS, Marroquin SR, Soriano FL, Garcia RB. The Transseptal Approach for Mitral Valve Replacement Revisited. Tex Heart Inst J 1997;24:209-14

[8] Kon ND, Tucker WY, Mills SA, Lavender SW, PAC, Cordel AR. Mitral Valve Operation via an Extended Transseptal Approach. Ann Thorac Surg 1993;55:1413-7

[9] Garcia-Villarreal OA, Gonzalez-Oviedo RG, Rodriguez-Gonzalez H, Martınez-Chapa HD. Superior septal approach for mitral valve surgery: a word of caution. European Journal of Cardio-thoracic Surgery 2003;24:862-867 
[10] Garcia-Villarreal OA. Superior septal approach for mitral valve surgery. Interact Cardio Vasc Thorac Surg 2016;22:249-51

[11] Guiraudon GM, Ofiesh JG, Kaushik R. Extended Vertical Transatrial Septal Approach to the Mitral Valve. Ann Thorac Surg 1991;52:1058-62

[12] Lukac P, Hjortdal VE, Pedersen AK, Mortesen PT, Jensen HK, Hansen PS. Superior transseptal approach to mitral valve is associated with a higher need for pacemaker implantation than the left atrial approach. Ann Thorac Surg 2007;83:77-82

[13] Takeshita M, Furuse A, Kotsuka Y, Kubota H. Sinus node function after mitral valve surgery via the transseptal superior approach. European Journal of Cardio-thoracic Surgery 1997;12:341-344

[14] Malik M, Kilic A. Biatrial transseptal approach for combined mitral valve and tricuspid valve operations. Operative Techniques in Thoracic and Cardiovascular Surgery 2015;20:2-16

[15] El Saegh MM, Aly MA, El Sayegh T, Mostafa EA, Zaghloul T, Saber W. Transseptal Approach for Mitral
Valve Surgery A Safe Alternative When the Need Call. Texas Heart Institute Journal 1993;20:23-7

[16] Wheatley D, Will M. Mitral valve replacement with mechanical or bioprosthetic valve. MMCTS 2004; 7 pages. doi:10.1510/mmcts.2004.001024

[17] Berreklouw E, Ercan H, Schonberger JP. Combined Superior-Transseptal Approach to the Left Atrium. Ann Thorac Surg 1991;51:293-5

[18] Borracci RA, Rrubio M, Milani A, Ramirez F, Barrero $C$, Rapallo CA, Ingino CA, Medrano JC. Transseptal Approach for Mitral Valve Replacement. Rev Argent Cardiol 2010;78:400-404

[19] Kara KA, Kartufan FF. Superior Septal Approach for Mitral Valve Surgery In case of Better Left Atrial Exposure. Biomedical Journal of Scientific and Technical Research 2018;9(5):7419-7422

[20] Mick SL, Keshavamurthy S, Gillinov AM. Mitral valve repair versus replacement. Ann Cardiothorac Surg 2015;4(3):230-237

\section{جراحة الصمام التاجي: مقارنة بين تقنية فتح الاذين الايسر و تقتية فتح الاذين الايمن والحاجز الاذيني و سقف الاذين الايسر}

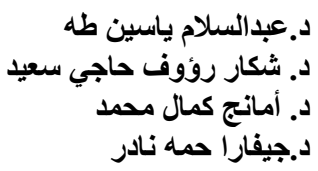

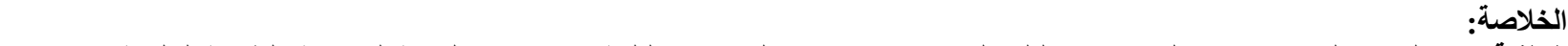

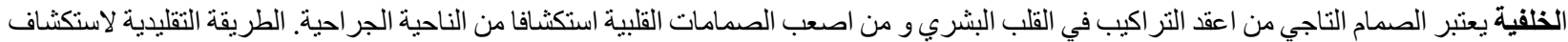

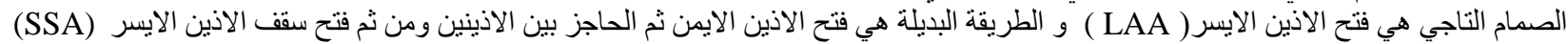

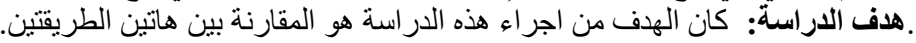

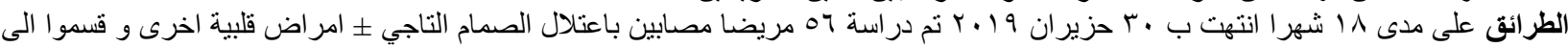

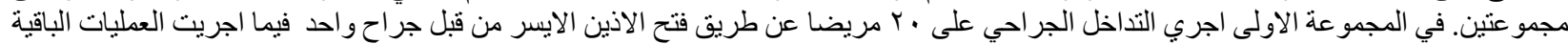

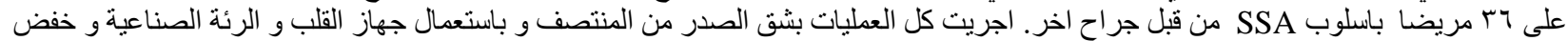

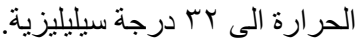

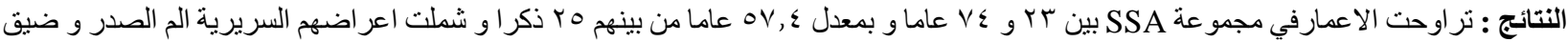

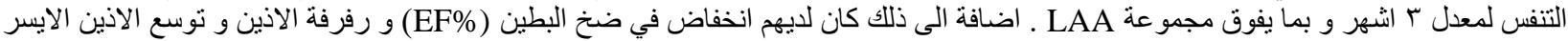

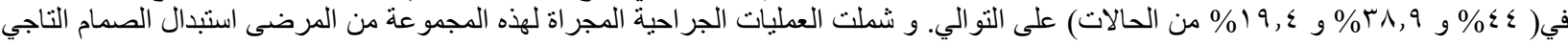

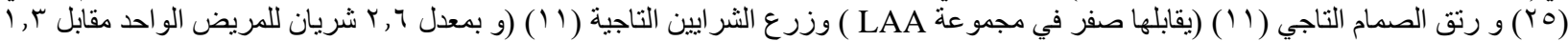

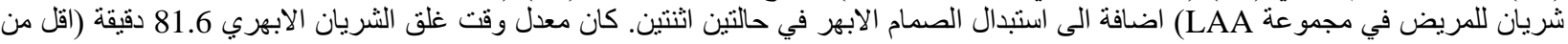

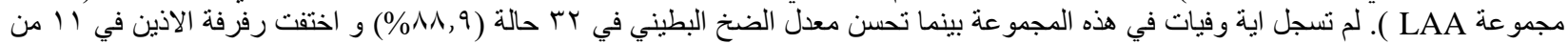

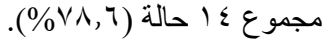

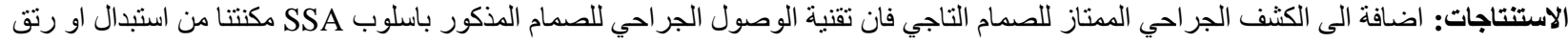

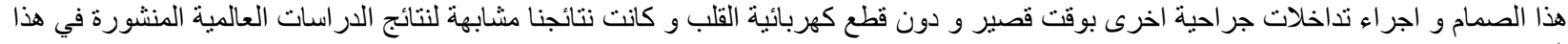
مفتاح الكلمات :الاذين الايسر، استكثاف الصمام التاجي، تقنية الاخول عن طريق الاذين الايسر، تقنية الدخول عن طريق اعلى الحاجز الاذيني. 